\title{
Occupational and environmental exposure to pesticides and cytokine pathways in chronic diseases (Review)
}

\author{
SILVIA GANGEMI $^{1 *}$, ELIZA GOFITA $^{2^{*}}$, CHIARA COSTA $^{3 *}$, MICHELE TEODORO $^{1}$, \\ GIUSI BRIGUGLIO ${ }^{1}$, DRAGANA NIKITOVIC ${ }^{4}$, GEORGE TZANAKAKIS ${ }^{4}$, ARISTIDES M. TSATSAKIS ${ }^{5}$, \\ MARTIN F. WILKS ${ }^{6}$, DEMETRIOS A. SPANDIDOS ${ }^{7}$ and CONCETTINA FENGA ${ }^{1}$
}

${ }^{1}$ Department of Biomedical, Odontoiatric, Morphological and Functional Images, Occupational Medicine Section,

'Policlinico G. Martino' Hospital, University of Messina, I-98125 Messina, Italy; ${ }^{2}$ Department of Toxicology,

Faculty of Pharmacy, University of Medicine and Pharmacy, 200349 Craiova, Romania; ${ }^{3}$ Department of Clinical and

Experimental Medicine, University of Messina, I-98125 Messina, Italy; ${ }^{4}$ Laboratory of Anatomy-Histology-Embryology, Medical School, University of Crete; ${ }^{5}$ Department of Forensic Sciences and Toxicology, Faculty of Medicine, University of Crete, Heraklion 71003, Greece; ${ }^{6}$ Swiss Centre for Applied Human Toxicology, University of Basel, CH-4055 Basel, Switzerland;

${ }^{7}$ Laboratory of Clinical Virology, Medical School, University of Crete, Heraklion 71003, Greece

Received May 4, 2016; Accepted August 23, 2016

DOI: $10.3892 / \mathrm{ijmm} .2016 .2728$

\begin{abstract}
Pesticides can exert numerous effects on human health as a consequence of both environmental and occupational exposures. The available knowledge base suggests that exposure to pesticides may result in detrimental reproductive changes, neurological dysfunction and several chronic disorders, which are defined by slow evolution and long-term duration. Moreover, an ever increasing amount of data have identified an association between exposure to pesticides and the harmful effects on the immune system. The real impact of alterations in humoral cytokine levels on human health, in particular in the case of chronic diseases, is still unclear. To date, studies have suggested that although exposure to pesticides can affect the immune system functionally, the development of immune disorders depends on the dose and duration of exposure to pesticides. However, many of the respective studies exhibit limitations, such as a lack of information on exposure levels,
\end{abstract}

Correspondence to: Professor Aristides M. Tsatsakis, Department of Forensic Sciences and Toxicology, Faculty of Medicine, University of Crete, Voutes, Heraklion 71003, Greece

E-mail: aris@med.uoc.gr

Professor Concettina Fenga, Department of Biomedical, Odontoiatric, Morphological and Functional Images, Occupational Medicine Section, 'Policlinico G. Martino' Hospital, University of Messina, Via Consolare Valeria, I-98125 Messina, Italy

E-mail: cfenga@unime.it

${ }^{*}$ Contributed equally

Key words: pesticides, occupational exposure, chronic diseases, immunotoxicity, cancer differences in the pesticide administration procedures, difficulty in characterizing a prognostic significance to the weak modifications often observed and the interpretation of obtained results. The main challenge is not just to understand the role of individual pesticides and their combinations, but also to determine the manner and the duration of exposure, as the toxic effects on the immune system cannot be separated from these considerations. There is a clear need for more well-designed and standardized epidemiological and experimental studies to recognize the exact association between exposure levels and toxic effects and to identify useful biomarkers of exposure. This review focuses on and critically discusses the immunotoxicity of pesticides and the impact of cytokine levels on health, focusing on the development of several chronic diseases.

\section{Contents}

1. Introduction

2. Data collection

3. Cancer

4. Parkinson's disease

5. Diabetes

6. Cardiovascular disease

7. Other chronic diseases

8. Limitations of the database

9. Conclusions

\section{Introduction}

Pesticides are widely utilized chemicals in agriculture, intended to preserve the productivity of crops and the quality of harvests. The term pesticide includes compounds of different chemical structures and specific mechanisms of action, which allow them to prevent, destroy, repel, or mitigate target pests (1). Based on 
their specific chemical structure, pesticides can be classified into various classes, e.g., carbamates, coumarin derivatives, organochlorine compounds, organophosphorus compounds and pyrethroids.

The universal use of assorted groups of pesticides causes global environmental pollution, as well as the accidental exposure of humans to these pesticides (2). Pesticides settle into the soil, are discharged into the groundwater and consecutively to rivers and seas, entering the food chain and thus, indirectly, human bodies. Environmental contamination is mostly significant in developing countries, where the use of pesticides is extensive and indiscriminate, while the inadequacy of preparation and equipment to carefully manage pesticides and the absence of strict control increase health risks (3). Of note, among the well-developed countries of the European Union (EU), Italy ranks first in the consumption of pesticides per agricultural area unit (4).

With regard to the general population, exposure to pesticides occurs at relatively low levels. Usually, at these doses of exposure, pesticides do not produce any permanent harmful effects to adult humans. However, several groups of individuals run a considerable risk either due to increased exposure (e.g., agricultural workers and their families; individuals who reside close to fields where pesticides are applied) or due to increased susceptibility to pesticide toxicity (e.g., children) (5-10). Health effects resulting from pesticide exposure via the dermal, oral, or inhalatory routes vary according to the specific compound involved and may be acute or chronic.

Experimental studies have reported that exposure to pesticides can exert damaging effects on the immune system (11-16). The immune system is a composite network of anatomical sites and various specialized cell types which are involved in the defence of an organism against potential pathogens and neoplastic cells (Fig. 1). The immune response consists of the antigen-non-specific response (innate) andthe antigen-specific one (adaptive). Immunocompetent cells secrete inflammatory mediators, such as cytokines, chemokines, and reactive oxygen species (ROS) and reactive nitrogen species (RNS). In particular, cytokines can regulate innate or adaptive immunity, hematopoiesis, inflammatory processes and many other cellular activities through specific binding to their respective receptors. It has been demonstrated that while in vitro cytokines can act alone, their in vivo actions are synergistic or antagonistic; thus they form an intercommunicative network that results from a delicate balance supporting homeostasis (17).

This balance shows vulnerability to the actions of a number of chemicals, including pesticides, leading to structural and functional alterations to the system, which ultimately result in a detrimental outcome.

The involvement of the immune system, contributing to the development of pathological conditions, has been previously demonstrated also in the context of different occupational risks $(18,19)$. Furthermore, work exposure to biological risks may cause infection from different agents that activate the immune response (20-22). Such an activation may induce specific B-cell clones to proliferate as a consequence of the chronic antigenic stimulation sustained by different infectious agents $(23,24)$. Moreover, the involvement of the tumor microenvironment along with cytokine release may be associated with tumor development in workers exposed to asbestos or to other fibers (25-27).

Although several studies have investigated the effects of exposure to pesticides on the cytokine network, the majority of these studies have analyzed the in vitro effects, whereas in vivo studies have mostly focused on animal models. Therefore, there is a discrepancy in the knowledge of the real impact of these alterations on humoral cytokine levels in humans and, in particular, on the minimum doses that can promote the development of chronic diseases. Herein, we reviewed the literature, focusing on the effects of occupational and environmental exposure to pesticides on cytokine pathways and on the impact of alterations in cytokine levels on health, with particular emphasis on the development of several chronic diseases.

\section{Data collection}

In the present review, data were obtained from a focused search of PubMed scientific databases in order to identify articles published in the English language correlating the exposure to pesticides with several chronic immune-related diseases. The majority of studies were identified through a PubMed search using the following terms: 'cancer', 'Parkinson's disease', 'Alzheimer's disease', 'diabetes', 'cardiovascular disease', 'reproductive disorder', 'development disorder' each in combination with 'pesticide' and 'immune system' or 'cytokine'.

Moreover, further publications were identified among the reference list of the screened articles. No restrictions were placed with regard to the country of origin, ethnicity, gender, environmental and occupational settings, or the type or date of publication (Fig. 2).

\section{Cancer}

The hypothesis of the possible association between exposure to pesticides and cancer has been widely investigated; the literature provides substantial evidence that chronic exposure to pesticides, even at low doses, in agricultural, commercial, domestic and garden administrations is associated with an increased risk of cancer, including prostate, lung, liver, breast and colon cancer, as well as non-Hodgkin lymphoma, leukemia and multiple myeloma (28-41).

A wide body of data have reported the ability of the immune system to recognize and control tumor growth. There seems to be a tight link between the risk of cancer and the immunotoxic effect of chemical compounds influencing the activity of natural killer (NK) and natural killer T (NKT) cells, macrophages, cytotoxic $\mathrm{T}$ cells and cytokine secretion: these alterations have been strongly suggested to affect cancer immunosurveillance, and several pesticides (organophosphates, organochlorines, dithiocarbamates and some fungicides) have been reported to induce the activation of these cells both in vitro, in vivo and in exposed human populations (42). Data from in vitro and in vivo studies have suggested that the immune system is able to recognize transformed cells, and now it is generally established that avoiding immune detection and elimination is a hallmark of cancer; on the contrary, it has become clear that the immune system can also promote tumor progression by promoting chronic inflammation, influencing tumor immunogenicity and suppressing antitumor immunity (43). 


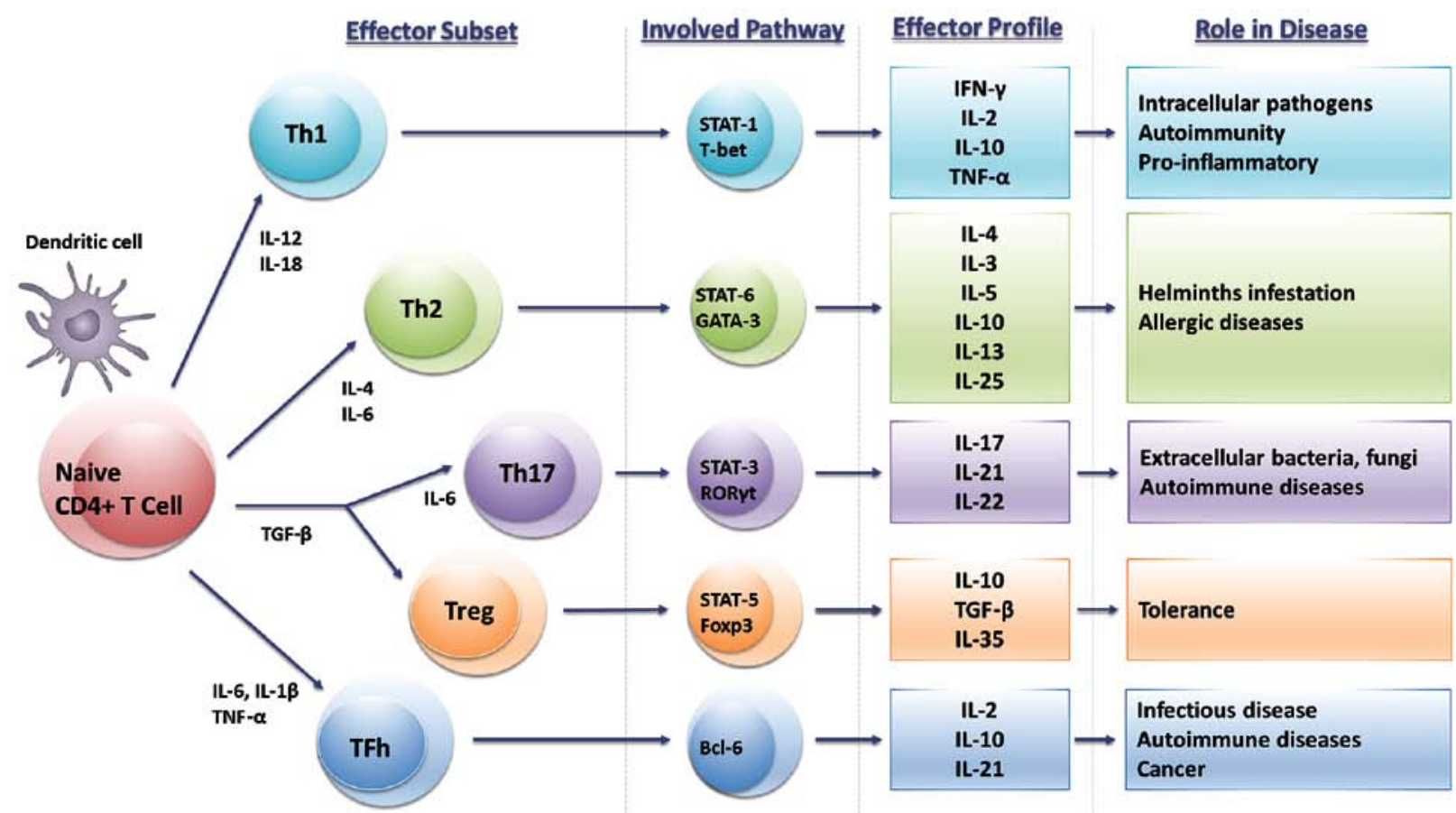

Figure 1. Immune system network. A schematic presentation of involved immune effector cell signaling in disease. TNF, tumor necrosis factor; TGF- $\beta$, transforming growth factor- $\beta$; IFN- $\gamma$, interferon- $\gamma$; IL, interleukin; Th1, T helper 1 ; STAT, signal transducer and activator of transcription..

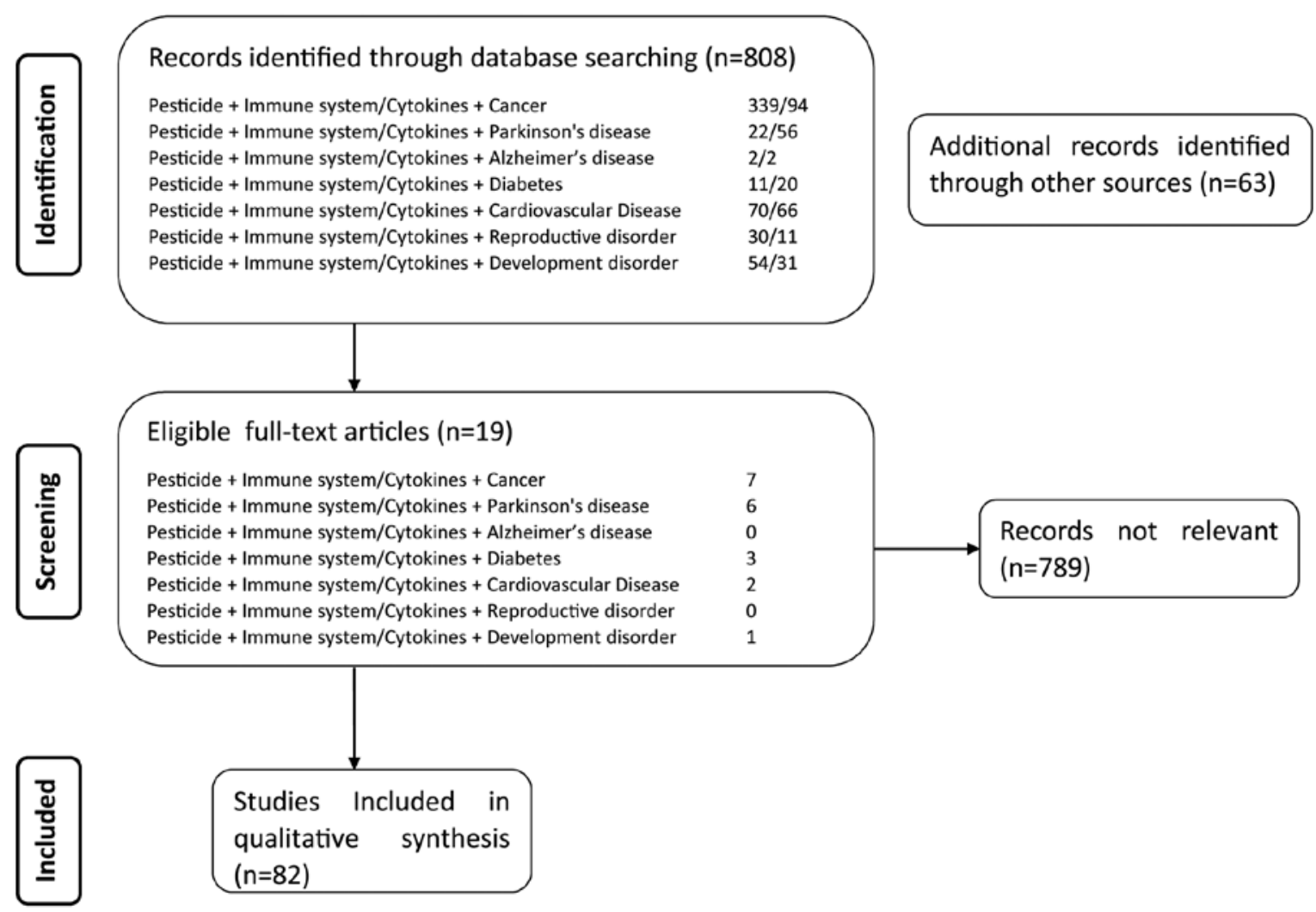

Figure 2. Pesticides and immune system induction in chronic diseases. Schematic presentation of results of a focused PubMed database search for a correlation between pesticide action and the modulation of cytokine pathways in chronic disease.

This dual role of the immune system in inhibiting or facilitating tumor growth is known as cancer immunoediting and consists of three phases: elimination (immune surveillance of cancer), equilibrium (with immunity controlling tumor expansion) and escape (tumor cells differentiate reducing their immunogenicity or inducing immunosuppressive mechanisms, 
leading to tumor growth). Chemical-induced immunotoxicity, due to pesticide exposure, can compromise any of the phases of immunoediting $(42,44)$.

Another possible mechanism of tumorigenicity is suggested by the evidence of neoplastic transformation of chronic inflammatory sites where pesticides can activate innate immune dysfunction, leading to chronic inflammation. Indeed, the increased production of growth factors required to repair tissues damaged by the increased secretion of inflammatory chemokines and cytokines [e.g., tumor necrosis factor (TNF), interleukin (IL)-1, -6 and -8] facilitates tumor cell growth $(16,45)$.

If note, our database search did not apprehend any study clearly including human pesticide exposure, cancer and cytokine expression. However, the putative association is strongly prompted by other publications suggesting that modifications in cytokine profiles and other immunological targets can increase cancer risk.

Cassidy et al investigated the correlation between exposure to some insecticides and breast cancer. In biopsies of women evaluated for breast lesions, they found a positive association between the presence of heptachlor epoxide and the prevalence of cancer (46). Moreover, when these authors exposed isolated human lymphocytes to heptachlor epoxide at concentrations similar to those found in breast biopsies, it was demonstrated that TNF- $\alpha$, in synergy with estrogens, induced DNA damage via nitric oxide (NO) signaling and initiated neoplastic transformation. In another study, the immunotoxicity of a synthetic pyrethroid was evaluated in 30 greenhouse workers occupationally exposed to $\alpha$-cypermethrin, by comparing the plasma levels of IL-1 $\beta$, IL-2, IL-4, IL-5, IL-6, IL-8, IL-10, IL-12p70, TNF- $\alpha$, TNF- $\beta$ and interferon (IFN) $-\gamma$. Exposed workers showed neither clinical signs of immunosuppression nor alterations in total leukocyte or leukocyte subpopulations, while significant differences $(\mathrm{p}<0.05)$ were demonstrated for IL-12p70 and highly significant differences $(\mathrm{p}<0.001)$ for IFN- $\gamma$, IL-2 and IL-8 levels. These findings are highly relevant since the respective mediators are implicated in antitumor immunity and response to infection. These results therefore, support the hypothesis that pyrethroid exposure may reduce host defenses against infection and cancer, mostly in subjects with decreased immune capacity (11).

We have previously investigated whether exposure to multiple pesticides (including neonicotinoids, pyrethroids and organophosphates), all suspected to be carcinogenic, can influence the Th17/Th22 network. IL-17 and IL-22 serum levels were analyzed in occupationally-exposed greenhouse workers, indicating a significant increase in the levels of IL-22, which has been established to be involved in cancer initiation from inflammation through the activation of the signal transducer and activator of transcription 3 (STAT-3) signaling pathway, while it promotes tumorigenesis via mitogen-activated protein kinase kinase kinase 8 (MAP3K8) signaling. Our results support the hypothesis that oxidative stress and impairment of Th1 lymphocyte function may affect host defenses against cancer in workers exposed to pesticides (12).

Recently, Dhouib et al reviewed the association between carbamate pesticide exposure, alterations in the immune system and susceptibility to different types of cancer. The authors concluded that carbamates can cause cancer through several non-immunological and immunological mechanisms, including oxidative stress, the suppression of cytokine production in T helper 1 (Th1) cells and the IFN- $\gamma$-induced production of NO in macrophages (47).

The study by Jorsaraei et al showed that carbaryl, another carbamate, reduced both the thymus and spleen weight in rats; in addition, carbaryl significantly decreased spleen lymphocyte proliferation and IL-2 production, altered the Th1/Th2 balance towards the Th2 response through the inhibition of IFN- $\gamma$ and the increase of IL-4 and IL-10 production, and also reduced pro-inflammatory cytokine (IL-1 $\beta$ and TNF- $\alpha$ ) production by macrophages (48). Thus, according to the same authors, carbaryl may promote cancer development through the utilization of immune response mechanisms.

Chlorpyrifos and its derivatives have also been implicated in carcinogenesis. In a recent study, an in vivo administration of chlorpyrifos to rats demonstrated a modest negative correlation between exposure levels and the number of NK cells, which are known to play an important role in cancer immunosurveillance (49). Moreover, it has been recently demonstrated that methyl parathion and chlorpyrifos promote the production of inflammatory citokines, such as TNF- $\alpha$, IL-6 and IL-1 $\beta$ in human hepatocellular carcinoma (HepG2) cells, thus negatively influencing the expression of the paraoxonase 1 (PON1) gene. Importantly, a decreased expression of the PON1 gene may increase susceptibility to organophosphate toxicity and the incidence of diseases related to chronic inflammation, such as hepatoceullular carcinogenesis $(1,50,51)$.

\section{Parkinson's disease}

Parkinson's disease (PD) is a neurodegenerative disease mostly affecting the motor system and is characterized by tremor, rigidity, postural reflex impairment and slowness. This debilitating condition is caused by the selective depletion of dopamine (DA) neurons in the substantia nigra pars compacta (SNpc) region and DA levels in the corpus striatum of the nigrostriatal DA pathway (52). DA neurons are particularly susceptible to oxidative stress owing to their low antioxidant capacity and elevated content of oxidation-prone molecules (DA, lipids and iron). The exact etiology and mechanisms of action of PD are still unclear.; however, there is strong evidence to suggest that glial reaction and neuroinflammation play a role in its pathogenesis (53).

Glial cell activation is a frequent characteristic both in patients and in animal models of PD, and microglia and astrocytes are considered to play pivotal roles in the neuroinflammatory processes related to PD development. Moreover, it has been hypothesized that the excessive activation of microglia leads to the increased induction of pro-inflammatory cytokines, such as TNF- $\alpha$, IL- $1 \beta$, IL- 6 and IFN- $\gamma$, inducing the degeneration of SNpc dopaminergic neurons. Furthermore, microglial activation promotes the release of pro-inflammatory mediators which are responsible for astrocyte activation, which in turn contributes to neuroinflammatory processes in PD (54).

Several studies have suggested that environmental factors, such as neurotoxins, pesticides, insecticides and DA itself may play a role in the pathophysiology of PD through the neurodegeneration of SNpc dopaminergic neurons, impairing mitochondrial function and activating microglia, thus 
finally inducing the accumulation of ROS and inflammatory factors (55-58).

PD is probably the neurological disease most frequently associated, by epidemiological studies, with exposure to pesticides in occupational or environmental settings. Overall, available data have provided sufficient evidence to establish an association between exposure to pesticides in general and an increased risk of developing PD; however, the evidence does not appear so convincing in order to confirm a causal association (59). Thus, experimental data on rodents have suggested that pesticide exposure represents a risk factor for PD. Importantly, paraquat and rotenone, known to cause neuroinflammation and dopaminergic cell loss, are the most common pesticides used to establish toxin-based animal models of PD (60-63). Moreover, Mitra et al demonstrated that treatment with paraquat caused behavioral impairment, as well as an increase in ROS and TNF- $\alpha$ levels in the substantia nigra in rats (64). In another study, Mangano et al demonstrated that a genetic deletion of IFN- $\gamma$ protected SNpc DA neurons from the harmful effects of paraquat, and normalized modifications in inflammatory and oxidative factors (IL-1 $\beta, T N F-\alpha$ ) within this brain region (65). Therefore, the authors concluded that IFN- $\gamma$ influences paraquat-induced neurodegeneration, implicating oxidative and pro-inflammatory pathways. Moreover, the release of TNF- $\alpha$ and IL- $1 \beta$ from microglial BV- 2 cells is also increased following treatment with rotenone as reported by Yuan et al (66). Exposure to some organochlorine pesticides, particularly dieldrin, has been shown to result in selective dopaminergic neurotoxicity that may be mediated by intracellular ROS production, regulating NOX2 and microglial activation (67-70). In another example of the deleterious effects of pesticides, the chronic subjection of rats to dichlorvos, an organophosphate insecticide, causes microglial activation with the induction of NADPH oxidase and pro-inflammatory cytokines (TNF- $\alpha$, IL-1 $\beta$ and IL-6) (71). It is important to note that microglial activation itself represents a risk factor for PD by enhancing the susceptibility of DA cells to dichlorvos toxicity (71).

\section{Diabetes}

Diabetes mellitus (DM) is a chronic progressive disease characterized by systemic hyperglycemia which results from alterations in insulin action, insulin secretion or both. DM, particularly type 2 , is considered a multifactorial disease in which genetics and lifestyle play a significant role, as well as environmental and occupational factors. Indeed, Raafat et al demonstrated a strong correlation between the blood concentration of malathion, an organophosphate insecticide, and insulin resistance among farmers (72).

Type $1 \mathrm{DM}$ is an autoimmune disease, in which the immune system incorrectly targets insulin-producing $\beta$-cells in the pancreas. Therefore, this type of diabetes can be considered an inflammatory disease (73). On the other hand, type 2 DM is a metabolic disorder associated with hyperglycemia, insulin resistance and a relative lack of insulin. This pathology seems to originate from alterations of the immune system, particularly as regards patterns of cytokine expression, resulting in a condition known as 'systemic low grade inflammation' (74). Furthermore, cytokines produced by adipose tissue, such as
TNF- $\alpha$ and IL-6, control the secretion of the C-reactive protein from the liver $(75,76)$. The stimulation of this inflammatory mechanism seems to be the trigger of insulin resistance in the peripheral tissues (77).

Recent epidemiological data have demonstrated a marked positive association between human exposure to organochlorines and organophosphate pesticides and DM (78). On the whole, a positive association of exposure with some organochlorine pesticides [trans-nonachlor, hexachlorobenzene, dichlorodiphenyltrichloroethane (DDT) and dichlorodiphenyldichloroethylene (DDE)] with type 2 diabetes has been evidenced. However, the available bibliographic data are not adequately numerous in order to confirm causality (79-81).

However, no human study, to date, to the best of our knowledge, has been performed focusing on the relation between DM or insulin resistance with mechanistic hypotheses which involve the cytokine network and pesticide exposure. Conversely, this putative association has been examined only in a few experimental studies in rodent models of insulin resistance. Thus, a recent study revealed that the increment of immune cells may be a consequence of the increased expression of cytokines, including IL-1, IL-6 and IFN- $\gamma$ in the liver of rats exposed to malathion (82). Moreover, Zhang et al demonstrated enhanced levels of malondialdehyde, TNF- $\alpha$ and IL- 6 in the muscles of rats exposed to omethoate, a commonly used insecticide in developing countries (83). The authors concluded with the postulation that omethoate has a potential to cause insulin resistance. Furthermore, a cross-sectional study suggested that farmers occupationally exposed to organophosphosphate pesticides are susceptible to developing neuropsychological disorders, as well as diabetes (84).

In addition, certain pesticides, belonging to the organochlorine family, seem to be linked with an enhanced risk of diabetes (85). Duramad et al investigated the effects of environmental exposure to pesticides in children during prenatal and early postnatal development; these authors hypothesized that changes in Th1/Th2 cytokine profiles are involved in the development of several disorders, such as respiratory diseases, allergies, cancer and diabetes (86).

Other studies have demonstrated increased levels of pro-inflammatory cytokines in rats exposed to organophosphates (87-89). Additionally, it has been demonstrated that the peripheral administration of IL- 6 induces hyperglycemia and insulin resistance in humans and rodents (90). A recent study hypothesized that organophosphate pesticides can attenuate the incretin effect and produce insulin resistance via lipotoxic effects, inflammatory stimulation and the induction of oxidative stress. Furthermore, organophosphates were found to cause $\beta$-cell dysfunction by overstimulation and the consequent downregulation of muscarinic receptors owing to the accumulation of acetylcholine (ACh), which plays a role in glucose-dependent insulin production (91).

\section{Cardiovascular disease}

Cardiovascular disease (CVD) represents the most important cause of death worldwide and the second most common cause of death in high-income countries. A great number of epidemiological studies have supported the correlation between exposure to pesticides and the development of CVD. 
A survey performed in Kenyan rural regions revealed that most of the active farm workers suffered from health problems related to the use of different agrochemical compounds. The study analyzed the association of various work tasks, such as horticulture, floriculture and greenhouse (those with a heavy application of agrochemicals) in order to detect cardiovascular symptoms (chest pain, palpitation and leg swelling) in respective workers. Indeed, a significant correlation between agrochemical exposure and CVD was detected (92). Moreover, a possible association has been suggested between the application of agrochemicals (including herbicides, phenoxy compounds, insecticides, fungicides, carbamates, organophosphates and organochlorines) with mortality due to CVD, such as ischemic heart disease and cerebrovascular accidents among farm workers (93).

According to the available literature, there is no study to date clearly including human pesticide exposure, CVD and cytokine expression, although a limited number of animal studies describing this complex association is available. Thus, Vadhana et al evaluated the effect of early life permethrin treatment on the hearts of adult rats (94). They reported higher levels of cholesterol, IL-1 $\beta$, IL- 2 , IL-10, IFN- $\gamma$ and Rantes in plasma, supporting the evidence that the modifications detected in adult rats may be the result of epigenetic alterations occurring during the neonatal age, leading to alterations in chemokines related to cardiac function. Zafiropoulos et al evaluated the effect of repeated low-level exposure to diazinon, propoxur and chlorpyrifos on the cardiac function of rabits and showed that these produce modifications in genomic DNA from cardiac tissues and increase the oxidative stress (95). In another study, following the administration of omethoate to rats, it was shown that the TNF- $\alpha$ level in cerebral tissue was significantly higher than that observed in the control group (96).

\section{Other chronic diseases}

There are a limited number of studies evaluating the correlation between exposure to pesticides and other respective chronic diseases in humans caused by cytokine dysregulation. This association however, still lacks robust support from bibliography. These conditions include: Alzheimer's disease (97-101), reproductive $(8,102-105)$ and neurodevelopmental disorders (106-109) which require further investigation for more proof.

\section{Limitations of the database}

Pesticides can exert various effects on human health by influencing the immune system in the case of both environmental and occupational exposure. Exposure to pesticides induces modifications in the immune system according to the specific pesticide and includes the alteration of well-regulated immune responses to tumor antigens, allergens, self-antigens and microbial antigens that can increase the susceptibility of the organism to develop various types of cancers, allergies, autoimmune and infectious diseases. However, the exact immunological mechanisms which underlie pesticide toxicity remain unclear.

Animal studies have demonstrated that specific pesticides can modify the immune system either morphologically or functionally. Nevertheless, in some cases, the concentrations or doses tested did not indicate relevant exposure concentrations for humans, thus the identification of a link between immunotoxic effects in animal models and human populations remains complex.

The exposure assessments in these studies were generally limited to evaluating broad categories of pesticides or target populations, which may conceal the involvement of specific pesticide or other agricultural exposure (110). Other limiting factors are exposure to a single pesticide in most immunotoxicity studies, while in real-life situations, individuals are exposed to a wide range of various chemicals and/or pesticides. Owing to the potential antagonism or synergistic effects of chemicals when they are mixed together, the toxicity and the resulting risks may differ as compared to their own effects. This is important in the case of individuals who are occupationally exposed, as the levels of combined pesticides to which humans are exposed to can achieve extremely high concentrations, particularly in manufacturing industries and circumscribed farming areas (111).

The studies which report immune system disorders in human exposed to pesticides have many limitations, such as a lack of information on exposure levels, differences in pesticide administration procedures, difficulty in characterizing a prognostic significance to the weak modifications often observed and the interpretation of obtained results. It seems that although the exposure to pesticides can affect immune function, the occurrence of immune disorders depends on the levels and duration of exposure to pesticides (112).

\section{Conclusions}

There is evidence from experimental and epidemiological studies to indicate that pesticide exposure may affect the immune system through disturbances of the cytokine balance. Equally, it is now well-established that the immune system plays an important role in the development of several chronic diseases. However, it is as yet not clear whether pesticide exposure may lead to chronic illness through direct or indirect effects on cytokines. The main challenge is not just to identify the effects of individual pesticides and their combinations on the immune system, but also to determine the way and the duration of exposure, since the toxic effects on the immune system cannot be separated from these considerations. Therefore, there is a clear need of more well-designed and standardized epidemiological and experimental studies to identify the exact association between exposure levels and toxic effects in order to establish novel biomarkers of exposure.

\section{References}

1. Costa C, Gangemi S, Giambò F, Rapisarda V, Caccamo D and Fenga $\mathrm{C}$ : Oxidative stress biomarkers and paraoxonase 1 polymorphism frequency in farmers occupationally exposed to pesticides. Mol Med Rep 12: 6353-6357, 2015.

2. Kapka-Skrzypczak L, Cyranka M, Skrzypczak M and Kruszewski M: Biomonitoring and biomarkers of organophosphate pesticides exposure - state of the art. Ann Agric Environ Med 18: 294-303, 2011.

3. farming on public and environmental health in The Netherlands, India, Ethiopia, and Uganda, considering the use of antibiotics and other agro-chemicals. Front Public Health 4: 12, 2016.

4. No authors listed: Infographic: pesticide planet. Science 341: 730-731, 2013. 
5. Coronado GD, Holte S, Vigoren E, Griffith WC, Barr DB, Faustman E and Thompson B: Organophosphate pesticide exposure and residential proximity to nearby fields: evidence for the drift pathway. J Occup Environ Med 53: 884-891, 2011.

6. Van Maele-Fabry G, Hoet P and Lison D: Parental occupational exposure to pesticides as risk factor for brain tumors in children and young adults: A systematic review and meta-analysis. Environ Int 56: 19-31, 2013.

7. Dolapsakis G, Vlachonikolis IG, Varveris C and Tsatsakis AM: Mammographic findings and occupational exposure to pesticides currently in use on Crete. Eur J Cancer 37: 1531-1536, 2001.

8. Mehrpour O, Karrari P, Zamani N, Tsatsakis AM and Abdollahi M: Occupational exposure to pesticides and consequences on male semen and fertility: A review. Toxicol Lett 230: $146-156,2014$

9. Tsakirakis A, Kasiotis KM, Arapaki N, Charistou A, Tsatsakis A, Glass CR and Machera K: Determination of operator exposure levels to insecticide during bait applications in olive trees: Study of coverall performance and duration of application. Int J Hyg Environ Health 214: 71-78, 2011.

10. García-García CR, Parrón T, Requena M, Alarcón R, Tsatsakis AM and Hernández AF: Occupational pesticide exposure and adverse health effects at the clinical, hematological and biochemical level. Life Sci 145: 274-283, 2016.

11. Costa C, Rapisarda V, Catania S, Di Nola C, Ledda C and Fenga C: Cytokine patterns in greenhouse workers occupationally exposed to $\alpha$-cypermethrin: An observational study. Environ Toxicol Pharmacol 36: 796-800, 2013.

12. Fenga C, Gangemi S, Catania S, De Luca A and Costa C: IL-17 and IL-22 serum levels in greenhouse workers exposed to pesticides. Inflamm Res 63: 895-897, 2014.

13. Chen D, Zhang Z, Yao H, Cao Y, Xing H and Xu S: Pro- and anti-inflammatory cytokine expression in immune organs of the common carp exposed to atrazine and chlorpyrifos. Pestic Biochem Physiol 114: 8-15, 2014.

14. Díaz-Resendiz KJ, Toledo-Ibarra GA and Girón-Pérez MI: Modulation of immune response by organophosphorus pesticides: fishes as a potential model in immunotoxicology. J Immunol Res 2015: 213836, 2015.

15. Ma J and Li X: Alteration in the cytokine levels and histopathological damage in common carp induced by glyphosate Chemosphere 128: 293-298, 2015.

16. Mokarizadeh A, Faryabi MR, Rezvanfar MA and Abdollahi M: A comprehensive review of pesticides and the immune dysregulation: Mechanisms, evidence and consequences. Toxicol Mech Methods 25: 258-278, 2015.

17. Brundage KM and Barnett JB: Immunotoxicity of pesticides. In: Hayes handbook of pesticide toxicology. Academic Press/Elsevier, New York, NY, pp483-497, 2010.

18. Gangemi S, Merendino RA, Minciullo PL, Ferlazzo B, Germanò D and Fenga C: Serum levels of interleukin-18 in subjects affected by occupational allergic contact dermatitis. J Dermatol Sci 33: 187-188, 2003.

19. Gangemi S, Rapisarda V, Minciullo PL, Di Pasquale G, Lombardo G, Valentino $M$ and Fenga $C$ : Circulating levels of interleukin-18 in asbestos-exposed workers. Toxicol Ind Health 21: 125-129, 2005 .

20. Fenga C, Cacciola A, Di Nola C, Calimeri S, Lo Giudice D, Pugliese M, Niutta PP and Martino LB: Serologic investigation of the prevalence of Chlamydophila psittaci in occupationally-exposed subjects in eastern Sicily. Ann Agric Environ Med 14: 93-96, 2007.

21. Rapisarda V, Marconi A, Candido S, Nicolosi D, Salmeri M, Gangemi P, Proietti L, Spandidos DA, Bracci M, Fenga C and Libra M: A tailored health surveillance program unveils a case of MALT lymphoma in an HCV-positive health-care worker. Oncol Lett 5: 651-654, 2013

22. Libra M, Mangano K, Anzaldi M, Quattrocchi C, Donia M, di Marco R, Signorelli S, Scalia G, Zignego AL, de Re V, et al: Analysis of interleukin (IL)-1 $\beta$ IL-1 receptor antagonist, soluble IL-1 receptor type II and IL-1 accessory protein in HCV-associated lymphoproliferative disorders. Oncol Rep 15 1305-1308, 2006.

23. Libra M, Polesel J, Russo AE, De Re V, Cinà D, Serraino D, Nicoletti F, Spandidos DA, Stivala F and Talamini R: Extrahepatic disorders of HCV infection: A distinct entity of B-cell neoplasia? Int J Oncol 36: 1331-1340, 2010

24. Ferreri AJ, Dolcetti R, Magnino S, Doglioni C and Ponzoni M: Chlamydial infection: The link with ocular adnexal lymphomas. Nat Rev Clin Oncol 6: 658-669, 2009.
25. Loreto C,Rapisarda V, Carnazza ML, Musumeci G, Valentino M, Fenga $C$ and Martinez G: Fluoro-edenite fibres induce lung cell apoptosis: An in vivo study. Histol Histopathol 23: 319-326, 2008.

26. Malaponte G, Hafsi S, Polesel J, Castellano G, Spessotto P, Guarneri C, Canevari S, Signorelli SS, McCubrey JA and Libra M: Tumor microenvironment in diffuse large B-cell lymphoma: Matrixmetalloproteinases activation is mediated by osteopontin overexpression. Biochim Biophys Acta 1863: 483-489, 2016.

27. Musumeci G, Cardile V, Fenga C, Caggia S and Loreto C: Mineral fibre toxicity: Expression of retinoblastoma (Rb) and phospho-retinoblastoma (pRb) protein in alveolar epithelial and mesothelial cell lines exposed to fluoro-edenite fibres. Cell Biol Toxicol 27: 217-225, 2011 .

28. Alavanja MC, Samanic C, Dosemeci M, Lubin J, Tarone R, Lynch CF, Knott C, Thomas K, Hoppin JA, Barker J, et al: Use of agricultural pesticides and prostate cancer risk in the Agricultural Health Study cohort. Am J Epidemiol 157: 800-814, 2003

29. Alavanja MC, Ross MK and Bonner MR: Increased cancer burden among pesticide applicators and others due to pesticide exposure. CA Cancer J Clin 63: 120-142, 2013.

30. Beane Freeman LE, Bonner MR, Blair A, Hoppin JA, Sandler DP, Lubin JH, Dosemeci M, Lynch CF, Knott C and Alavanja MC: Cancer incidence among male pesticide applicators in the Agricultural Health Study cohort exposed to diazinon. Am J Epidemiol 162: 1070-1079, 2005.

31. Fenga C: Occupational exposure and risk of breast cancer. Biomed Rep 4: 282-292, 2016.

32. Gomaa AI, Khan SA, Toledano MB, Waked I and Taylor-Robinson SD: Hepatocellular carcinoma: Epidemiology, risk factors and pathogenesis. World J Gastroenterol 14: 4300-4308, 2008.

33. Khuder SA and Mutgi AB: Meta-analyses of multiple myeloma and farming. Am J Ind Med 32: 510-516, 1997.

34. Lee WJ, Blair A, Hoppin JA, Lubin JH, Rusiecki JA, Sandler DP, Dosemeci $\mathrm{M}$ and Alavanja MC: Cancer incidence among pesticide applicators exposed to chlorpyrifos in the Agricultural Health Study. J Natl Cancer Inst 96: 1781-1789, 2004.

35. Lee WJ, Sandler DP, Blair A, Samanic C, Cross AJ and Alavanja MC: Pesticide use and colorectal cancer risk in the Agricultural Health Study. Int J Cancer 121: 339-346, 2007.

36. Merhi M, Raynal H, Cahuzac E, Vinson F, Cravedi JP and Gamet-Payrastre L: Occupational exposure to pesticides and risk of hematopoietic cancers: Meta-analysis of case-control studies. Cancer Causes Control 18: 1209-1226, 2007.

37. Purdue MP, Hoppin JA, Blair A, Dosemeci M and Alavanja MC: Occupational exposure to organochlorine insecticides and cancer incidence in the Agricultural Health Study. Int J Cancer 120: 642-649, 2007.

38. Vakonaki E, Androutsopoulos VP, Liesivuori J, Tsatsakis AM and Spandidos DA: Pesticides and oncogenic modulation. Toxicology 307: 42-45, 2013.

39. Duke TJ, Jahed NC, Veneroso CC, Da Roza R, Johnson O, Hoffman D, Barsky SH and Levine PH: A cluster of inflammatory breast cancer (IBC) in an office setting: Additional evidence of the importance of environmental factors in IBC etiology. Oncol Rep 24: 1277-1284, 2010.

40. Belpomme D, Irigaray P, Ossondo M, Vacque D and Martin M: Prostate cancer as an environmental disease: An ecological study in the French Caribbean islands, Martinique and Guadeloupe. Int J Oncol 34: 1037-1044, 2009.

41. Hardell L, Eriksson M and Degerman A: Metaanalysis of 4 Swedish case-control studies on exposure to pesticides as risk-factor for soft-tissue sarcoma including the relation to tumor-localization and histopathological type. Int J Oncol 6: 847-851, 1995

42. Corsini E, Sokooti M, Galli CL, Moretto A and Colosio C: Pesticide induced immunotoxicity in humans: A comprehensive review of the existing evidence. Toxicology 307: 123-135, 2013.

43. Teng MW, Galon J, Fridman WH and Smyth MJ: From mice to humans: Developments in cancer immunoediting. J Clin Invest 125: 3338-3346, 2015.

44. Dunn GP, Old LJ and Schreiber RD: The three Es of cancer immunoediting. Annu Rev Immunol 22: 329-360, 2004.

45. Grivennikov SI and Karin M: Inflammatory cytokines in cancer: Tumour necrosis factor and interleukin 6 take the stage. Ann Rheum Dis 70 (Suppl 1): i104-i108, 2011. 
46. Cassidy RA, Natarajan S and Vaughan GM: The link between the insecticide heptachlor epoxide, estradiol, and breast cancer. Breast Cancer Res Treat 90: 55-64, 2005.

47. Dhouib I, Jallouli M, Annabi A, Marzouki S, Gharbi N, Elfazaa S and Lasram MM: From immunotoxicity to carcinogenicity: The effects of carbamate pesticides on the immune system. Environ Sci Pollut Res Int 23: 9448-9458, 2016.

48. Jorsaraei SG, Maliji G, Azadmehr A, Moghadamnia AA and Faraji AA: Immunotoxicity effects of carbaryl in vivo and in vitro. Environ Toxicol Pharmacol 38: 838-844, 2014.

49. Noworyta-Głowacka J, Beresińska M, Bańkowski R, Wiadrowska B, Siennicka J and Ludwicki JK: Effect of chlorpyrifos on the profile of subpopulations immunocompetent cells $\mathrm{B}, \mathrm{T}$ and NK in in vivo model. Rocz Panstw Zakl Hig 65: 311-316, 2014.

50. Jung IH, Choi JH, Chung YY, Lim GL, Park YN and Park SW: Predominant Activation of JAK/STAT3 Pathway by Interleukin-6 Is Implicated in Hepatocarcinogenesis. Neoplasia 17: 586-597, 2015.

51. Medina-Díaz IM, Ponce-Ruiz N, Ramírez-Chávez B, Rojas-García AE, Barrón-Vivanco BS, Elizondo G and Bernal-Hernández YY: Downregulation of human paraoxonase 1 (PON1) by organophosphate pesticides in HepG2 cells. Environ Toxicol: Mar 7, 2016 (Epub ahead of print).

52. Kish SJ, Shannak K, Rajput A, Deck JH and Hornykiewicz O: Aging produces a specific pattern of striatal dopamine loss: Implications for the etiology of idiopathic Parkinson's disease. J Neurochem 58: 642-648, 1992.

53. Blesa J, Trigo-Damas I, Quiroga-Varela A and Jackson-Lewis VR: Oxidative stress and Parkinson's disease. Front Neuroanat 9: 91, 2015.

54. Hong H, Kim BS and Im HI: Pathophysiological role of neuroinflammation in neurodegenerative diseases and psychiatric disorders. Int Neurourol J 20 (Suppl 1): S2-S7, 2016.

55. Baltazar MT, Dinis-Oliveira RJ, de Lourdes Bastos M, Tsatsakis AM, Duarte JA and Carvalho F: Pesticides exposure as etiological factors of Parkinson's disease and other neurodegenerative diseases - a mechanistic approach. Toxicol Lett 230 85-103, 2014

56. Freire $\mathrm{C}$ and Koifman S: Pesticide exposure and Parkinson's disease: Epidemiological evidence of association. Neurotoxicology 33: 947-971, 2012.

57. Van Maele-Fabry G, Hoet P, Vilain F and Lison D: Occupational exposure to pesticides and Parkinson's disease: A systematic review and meta-analysis of cohort studies. Environ Int 46: $30-43,2012$

58. Dardiotis E, Xiromerisiou G, Hadjichristodoulou C, Tsatsakis AM, Wilks MF and Hadjigeorgiou GM: The interplay between environmental and genetic factors in Parkinson's disease susceptibility: The evidence for pesticides. Toxicology 307: $17-23,2013$.

59. Moretto A and Colosio C: The role of pesticide exposure in the genesis of Parkinson's disease: Epidemiological studies and experimental data. Toxicology 307: 24-34, 2013

60. Litteljohn D, Mangano E, Clarke M, Bobyn J, Moloney K and Hayley S: Inflammatory mechanisms of neurodegeneration in toxin-based models of Parkinson's disease. Parkinsons Dis 2011: 713517,2010

61. Mitra S, Chakrabarti N, Dutta SS, Ray S, Bhattacharya P, Sinha P and Bhattacharyya A: Gender-specific brain regional variation of neurons, endogenous estrogen, neuroinflammation and glial cells during rotenone-induced mouse model of Parkinson's disease. Neuroscience 292: 46-70, 2015.

62. Panaro MA and Cianciulli A: Current opinions and perspectives on the role of immune system in the pathogenesis of Parkinson's disease. Curr Pharm Des 18: 200-208, 2012.

63. Taetzsch T and Block ML: Pesticides, microglial NOX2, and Parkinson's disease. J Biochem Mol Toxicol 27: 137-149, 2013

64. Mitra S, Chakrabarti N and Bhattacharyya A: Differential regional expression patterns of $\alpha$-synuclein, TNF- $\alpha$, and IL-1 $\beta$; and variable status of dopaminergic neurotoxicity in mouse brain after Paraquat treatment. J Neuroinflammation 8: 163, 2011.

65. Mangano EN, Litteljohn D, So R, Nelson E, Peters S, Bethune C, Bobyn J and Hayley S: Interferon- $\gamma$ plays a role in paraquat-induced neurodegeneration involving oxidative and proinflammatory pathways. Neurobiol Aging 33: 1411-1426, 2012.

66. Yuan YH, Sun JD, Wu MM, Hu JF, Peng SY and Chen NH: Rotenone could activate microglia through $\mathrm{NF \kappa B}$ associated pathway. Neurochem Res 38: 1553-1560, 2013.
67. Liu B, Gao HM and Hong JS: Parkinson's disease and exposure to infectious agents and pesticides and the occurrence of brain injuries: Role of neuroinflammation. Environ Health Perspect 111: 1065-1073, 2003.

68. Gao HM, Liu B, Zhang W and Hong JS: Synergistic dopaminergic neurotoxicity of MPTP and inflammogen lipopolysaccharide: Relevance to the etiology of Parkinson's disease. FASEB J 17: 1957-1959, 2003

69. Hatcher JM, Richardson JR, Guillot TS, McCormack AL, Di Monte DA, Jones DP, Pennell KD and Miller GW: Dieldrin exposure induces oxidative damage in the mouse nigrostriatal dopamine system. Exp Neurol 204: 619-630, 2007.

70. Weisskopf MG, Knekt P, O'Reilly EJ, Lyytinen J, Reunanen A, Laden F, Altshul L and Ascherio A: Persistent organochlorine pesticides in serum and risk of Parkinson disease. Neurology 74: $1055-1061,2010$

71. Binukumar BK, Bal A and Gill KD: Chronic dichlorvos exposure: microglial activation, proinflammatory cytokines and damage to nigrostriatal dopaminergic system. Neuromolecular Med 13: 251-265, 2011.

72. Raafat N, Abass MA and Salem HM: Malathion exposure and insulin resistance among a group of farmers in Al-Sharkia governorate. Clin Biochem 45: 1591-1595, 2012.

73. Donath MY and Shoelson SE: Type 2 diabetes as an inflammatory disease. Nat Rev Immunol 11: 98-107, 2011.

74. Duncan BB, Schmidt MI, Pankow JS, Ballantyne CM, Couper D, Vigo A, Hoogeveen R, Folsom AR and Heiss G; Atherosclerosis Risk in Communities Study: Low-grade systemic inflammation and the development of type 2 diabetes: The atherosclerosis risk in communities study. Diabetes 52: 1799-1805, 2003.

75. Wellen KE and Hotamisligil GS: Inflammation, stress, and diabetes. J Clin Invest 115: 1111-1119, 2005.

76. Zhang K, Shen X, Wu J, Sakaki K, Saunders T, Rutkowski DT, Back SH and Kaufman RJ: Endoplasmic reticulum stress activates cleavage of CREBH to induce a systemic inflammatory response. Cell 124: 587-599, 2006.

77. Yudkin JS, Stehouwer CD, Emeis JJ and Coppack SW: C-reactive protein in healthy subjects: associations with obesity, insulin resistance, and endothelial dysfunction: a potential role for cytokines originating from adipose tissue? Arterioscler Thromb Vasc Biol 19: 972-978, 1999.

78. Swaminathan K: Pesticides and human diabetes: A link worth exploring? Diabet Med 30: 1268-1271, 2013.

79. Taylor KW, Novak RF, Anderson HA, Birnbaum LS, Blystone C, Devito M, Jacobs D, Köhrle J, Lee DH, Rylander L, et al: Evaluation of the association between persistent organic pollutants (POPs) and diabetes in epidemiological studies: A national toxicology program workshop review. Environ Health Perspect 121: 774-783, 2013.

80. Jaacks LM and Staimez LR: Association of persistent organic pollutants and non-persistent pesticides with diabetes and diabetes-related health outcomes in Asia: A systematic review. Environ Int 76: 57-70, 2015.

81. Magliano DJ, Loh VH, Harding JL, Botton J and Shaw JE: Persistent organic pollutants and diabetes: A review of the epidemiological evidence. Diabetes Metab 40: 1-14, 2014.

82. Lasram MM, Dhouib IB, Bouzid K, Lamine AJ, Annabi A, Belhadjhmida N, Ahmed MB, Fazaa SE, Abdelmoula J and Gharbi N: Association of inflammatory response and oxidative injury in the pathogenesis of liver steatosis and insulin resistance following subchronic exposure to malathion in rats. Environ Toxicol Pharmacol 38: 542-553, 2014.

83. Zhang Y, Ren M, Li J, Wei Q, Ren Z, Lv J, Niu F and Ren S: Does omethoate have the potential to cause insulin resistance? Environ Toxicol Pharmacol 37: 284-290, 2014

84. Malekirad AA, Faghih M, Mirabdollahi M, Kiani M, Fathi A and Abdollahi M: Neurocognitive, mental health, and glucose disorders in farmers exposed to organophosphorus pesticides. Arh Hig Rada Toksikol 64: 1-8, 2013.

85. Starling AP, Umbach DM, Kamel F, Long S, Sandler DP and Hoppin JA: Pesticide use and incident diabetes among wives of farmers in the Agricultural Health Study. Occup Environ Med 71: 629-635, 2014

86. Duramad P, Tager IB and Holland NT: Cytokines and other immunological biomarkers in children's environmental health studies. Toxicol Lett 172: 48-59, 2007.

87. Ayub S, Verma J and Das N: Effect of endosulfan and malathion on lipid peroxidation, nitrite and TNF-alpha release by rat peritoneal macrophages. Int Immunopharmacol 3: 1819-1828, 2003. 
88. Hariri AT, Moallem SA, Mahmoudi M, Memar B and Hosseinzadeh $\mathrm{H}$ : Sub-acute effects of diazinon on biochemical indices and specific biomarkers in rats: Protective effects of crocin and safranal. Food Chem Toxicol 48: 2803-2808, 2010.

89. Yurumez Y, Cemek M, Yavuz Y, Birdane YO and Buyukokuroglu ME: Beneficial effect of N-acetylcysteine against organophosphate toxicity in mice. Biol Pharm Bull 30: 490-494, 2007.

90.Zou C and Shao J: Role of adipocytokines in obesity-associated insulin resistance. J Nutr Biochem 19: 277-286, 2008.

91.Rathish D, Agampodi SB, Jayasumana MA and Siribaddana SH: From organophosphate poisoning to diabetes mellitus: The incretin effect. Med Hypotheses 91: 53-55, 2016.

92. Tsimbiri PF, Moturi WN, Sawe J, Henley P and Bend JR: Health impact of pesticides on residents and horticultural workers in the lake Naivash region, Kenya. Occup Dis Environ Med 3: 24-34, 2015

93. Weichenthal S, Villeneuve PJ, Burnett RT, van Donkelaar A, Martin RV, Jones RR, DellaValle CT, Sandler DP, Ward MH and Hoppin JA: Long-term exposure to fine particulate matter: Association with nonaccidental and cardiovascular mortality in the agricultural health study cohort. Environ Health Perspect 122: 609-615, 2014.

94. Vadhana MS, Carloni M, Nasuti C, Fedeli D and Gabbianelli R: Early life permethrin insecticide treatment leads to heart damage in adult rats. Exp Gerontol 46: 731-738, 2011.

95.Zafiropoulos A, Tsarouhas K, Tsitsimpikou C, Fragkiadaki P, Germanakis I, Tsardi M, Maravgakis G, Goutzourelas N, Vasilaki F, Kouretas D, et al: Cardiotoxicity in rabbits after a low-level exposure to diazinon, propoxur, and chlorpyrifos. Hum Exp Toxicol 33: 1241-1252, 2014

96. Wang T, Jiang N, Han B, Liu W, Liu T, Fu F and Zhao D: Escin attenuates cerebral edema induced by acute omethoate poisoning. Toxicol Mech Methods 21: 400-405, 2011.

97. Campdelacreu J: Parkinson disease and Alzheimer disease: Environmental risk factors. Neurologia 29: 541-549, 2014.

98. Chin-Chan M, Navarro-Yepes J and Quintanilla-Vega B: Environmental pollutants as risk factors for neurodegenerative disorders: Alzheimer and Parkinson diseases. Front Cell Neurosci 9: 124, 2015.

99. Hayden KM, Norton MC, Darcey D, Ostbye T, Zandi PP, Breitner JC and Welsh-Bohmer KA; Cache County Study Investigators: Occupational exposure to pesticides increases the risk of incident AD: The Cache County study. Neurology 74 : 1524-1530, 2010.

100. Richardson JR, Roy A, Shalat SL, von Stein RT, Hossain MM, Buckley B, Gearing M, Levey AI and German DC: Elevated serum pesticide levels and risk for Alzheimer disease. JAMA Neurol 71: 284-290, 2014.
101.Zaganas I, Kapetanaki S, Mastorodemos V, Kanavouras K, Colosio C, Wilks MF and Tsatsakis AM: Linking pesticide exposure and dementia: What is the evidence? Toxicology 307: 3-11, 2013.

102. Den Hond E, Tournaye H, De Sutter P, Ombelet W, Baeyens W, Covaci A, Cox B, Nawrot TS, Van Larebeke N and D'Hooghe T: Human exposure to endocrine disrupting chemicals and fertility: A case-control study in male subfertility patients. Environ Int 84: 154-160, 2015

103. Jamal F, Haque QS, Singh S and Rastogi S: The influence of organophosphate and carbamate on sperm chromatin and reproductive hormones among pesticide sprayers. Toxicol Ind Health: Jan 29, 2015 (Epub ahead of print).

104. Miranda-Contreras L, Cruz I, Osuna JA, Gómez-Pérez R, Berrueta L, Salmen S, Colmenares M, Barreto S, Balza A, Morales Y, et al: Effects of occupational exposure to pesticides on semen quality of workers in an agricultural community of Merida state, Venezuela. Invest Clin 56: 123-136, 2015 (In Spanish).

105. Radwan M, Jurewicz J, Wielgomas B, Piskunowicz M, Sobala W, Radwan P, Jakubowski L, Hawuła W and Hanke W: The association between environmental exposure to pyrethroids and sperm aneuploidy. Chemosphere 128: 42-48, 2015.

106. Furlong MA, Engel SM, Barr DB and Wolff MS: Prenatal exposure to organophosphate pesticides and reciprocal social behavior in childhood. Environ Int 70: 125-131, 2014.

107. Ornoy A, Weinstein-Fudim L and Ergaz Z: Prenatal factors associated with autism spectrum disorder (ASD). Reprod Toxicol 56: 155-169, 2015.

108. Shelton JF, Geraghty EM, Tancredi DJ, Delwiche LD, SchmidtRJ, Ritz B, Hansen RL and Hertz-Picciotto I: Neurodevelopmental disorders and prenatal residential proximity to agricultural pesticides: The CHARGE study. Environ Health Perspect 122: 1103-1109, 2014

109. Vrijheid M, Casas M, Gascon M, Valvi D and Nieuwenhuijsen M: Environmental pollutants and child health-A review of recent concerns. Int J Hyg Environ Health 219: 331-342, 2016.

110. Aschebrook-Kilfoy B, Ward MH, Della Valle CT and Friesen MC: Occupation and thyroid cancer. Occup Environ Med 71: 366-380, 2014.

111. Voccia I, Blakley B, Brousseau $\mathrm{P}$ and Fournier M: Immunotoxicity of pesticides: A review. Toxicol Ind Health 15: 119-132, 1999.

112. Taghavian F, Vaezi G, Abdollahi M and Malekirad AA: Comparative Toxicological Study between Exposed and Non-Exposed Farmers to Organophosphorus Pesticides. Cell J 18: 89-96, 2016 